\title{
The evidence for rural road technology in low-income countries
}

Michael Peter Nicholas Burrow MA(Cantab), PhD, MCIHT Senior Lecturer, Civil Engineering, School of Engineering,

University of Birmingham, Birmingham, UK (corresponding author: m.p.n.burrow@bham.ac.uk)

Harry Evdorides Dipl.-Ing., PhD, CEng, Eurlng, MCIHT Lecturer, Civil Engineering, School of Engineering,

University of Birmingham, Birmingham, UK

Gurmel Singh Ghataora BSC, PhD

Senior Lecturer, Civil Engineering, School of Engineering,

University of Birmingham, Birmingham, UK
Robert Petts BSC, MICE, MCHIT, MIAE

Honorary Senior Lecturer, Civil Engineering, School of Engineering, University of Birmingham, Birmingham, UK

Martin S. Snaith OBE, MA, BAI, MSC, PhD, ScD, FICE, FCIHT, FREng Emeritus Professor, Civil Engineering, School of Engineering, University of Birmingham, Birmingham, UK

Rural road networks in low-income countries (LICS) and low/middle-income countries (LMICs) are critical for economic and social well-being. However, they are mostly unpaved, are of poor average condition, can be impassable after periods of rain and have high user costs. There is therefore a need to identify low-cost, proven sustainable solutions for rural roads in these countries. To this end, the UK Department for International Development commissioned a systematic review to identify and appraise technologies appropriate for low-volume rural roads that have enabled improved and sustainable rural access in LICs and LMICs. Its findings are summarised in this paper. The review found that there is an evidence base of engineering-related technologies (primarily associated with the use of materials and design philosophies) that could be used to improve the performance of gravel or earth rural roads and that proper construction and appropriate maintenance are vital for the technologies to be sustainable in physical terms. However, the review argues that, since there are few empirical studies demonstrating the sustainability of rural road technologies, expert knowledge is needed to support the implementation of its findings.

\section{Background}

It is estimated that around a billion of the world's population do not have reliable all-season road access and, as a result, social and economic development is substantially constrained (Lebo and Schelling, 2001). In particular, rural communities in low-income countries (LICs) and low/middle-income countries (LMICs) rely completely on access to low-volume rural roads (LVRRs) for the pursuit of social interaction, access to schools, health facilities, the workplace, markets and basic needs such as clean water (Akpan, 2014; Knox et al., 2013). However, the vast majority of these roads are unpaved (typically more than $90 \%$ ) and suffer from inadequate maintenance.

Predominantly, LVRRs in LICs and LMICs are earth or are made from gravel. Earth surfaces are normally unable to provide all-season access in many regions, and both of these low-cost surface types require regular routine maintenance of camber and drainage systems. Gravel surfaces also require regular periodic maintenance to replace gravel loss, which can be extreme in many environments, and is relatively expensive compared with the road's initial cost. Replacing lost gravel, which is a finite resource, can be unsustainable. As a result, LVRRs in LICs and LMICs are often in poor condition, can be impassable after periods of rain and have high road-user costs. Climate change is exacerbating this situation as many regions in LICs and LMICs are experiencing more extreme weather events.

The UK Department for International Development (DFID) commissioned a systematic review of the literature with the aim of identifying and appraising technologies appropriate for LVRRs that have enabled improved and sustainable lowvolume rural access in LICs and LMICs. This paper describes the results of the review and discusses how expert knowledge can be included within the process to enable the findings to be adequately applied.

\section{Systematic review}

Often used to inform policy and practice, a systematic review is a critical appraisal and synthesis of research findings carried out using explicit, systematic and transparent methods (Gough et al., 2013). The systematic review described in this paper addressed the following questions.

What is the evidence supporting the technology selection for LVRRs in LICs and LMICs?

What evidence is there to support the sustainability of different rural road technologies? 


\subsection{Definitions}

The systematic review followed a search protocol based on the following definitions. The World Bank's definition of countries was used to identify LICs and LMICs (WB, 2015). LVRRs were considered to be roads with an annual average daily traffic (AADT) of up to 300 motor vehicles per day (mvpd) and a design cumulative traffic load of less than 0.5 million equivalent standard axles (ESAs).

Technology for LVRRs was considered to be associated with the planning and building of new roads, providing all-season access through upgrading existing earth and gravel roads, and carrying out maintenance. Technology therefore was taken to include

- resources (materials, labour, equipment, capital/credit)

management tools (e.g. for economic appraisal, planning, computer software)

- design, construction and maintenance methods.

The review focused on studies reporting a range of outcomes associated with the implementation of LVRR technology. A technology was considered to be sustainable if it had ensured the capability of an LVRR to perform to its planned, designed and constructed standards, with the available financial and physical resources, using local operational arrangements and in the local environment.

\subsection{The search approach adopted}

The review questions lent themselves to an unbiased aggregation approach to identify studies that demonstrate the sustainable use of technology in different contexts (Gough et al., 2013). The strategy tried to identify longitudinal studies that had been carried out over a significant part of the life cycle of an LVRR. The sources used were websites of organisations involved in the road sector, bibliographic databases, internet search engines, hard copies of books and journals, reference lists and professional reports. A systematic review software application (EPPI-Reviewer 4) facilitated the review and was used for screening, coding, analysing and storing retrieved documents (Thomas et al., 2010). The search process is summarised in Figure 1.

\subsection{Weight of evidence: assessing the quality of studies}

A weight of evidence (WoE) framework was used to assess the quality and relevance of the included studies in three categories - soundness of the study, appropriateness of study design for answering the review question and relevance of the study focus to the review (see Table 1). The studies considered were required to achieve a high rating in at least two categories and a medium rating in the third.

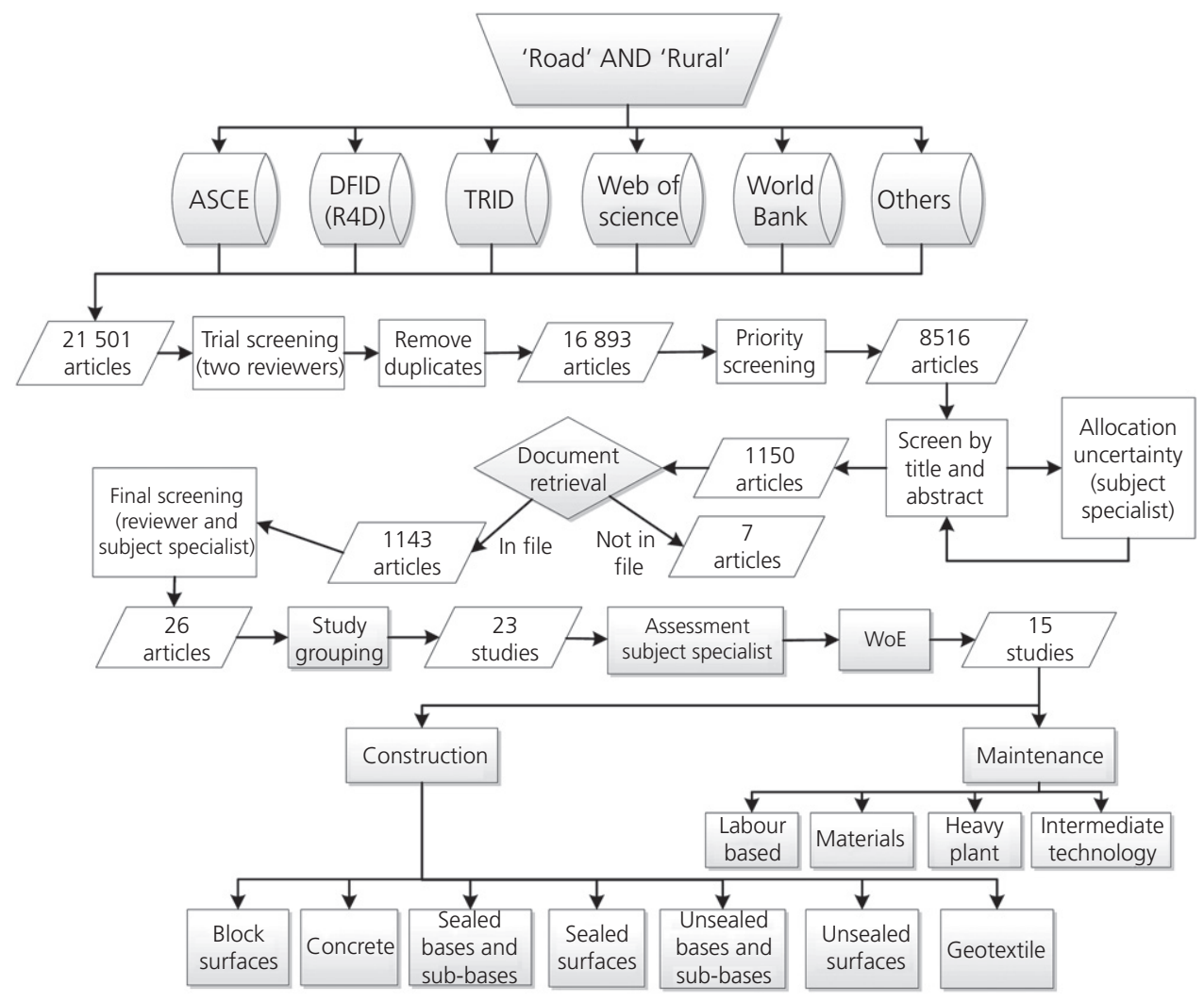

Figure 1. The search process 
Weight of evidence

\section{Soundness}

- High: Explicit and detailed methods and results for data collection and analysis; interpretation soundly based on findings; critical comparison with other work

- Medium: Satisfactory methods and results; interpretation partially warranted by findings

- Low: methods and results sections unsatisfactory; no interpretation of findings or interpretation not warranted by findings

Appropriateness of study design

- High: Road pavement trials covering at least two periodic maintenance cycles (approximately 4-10 years). Road condition data to be collected at least annually and the frequency and type of maintenance carried out recorded. Alternatively, slice-in-time studies of a selection of in-service LVRRs of ages varying from 3 years to at least 12 years. Road condition assessed at the end of dry and wet seasons

- Medium: Trials lasting one periodic maintenance cycle (2-5 years). Road condition data collected periodically during this time. Slice-in-time studies to include a selection of in-service LVRRs of ages varying from at least 2 years to at least 5 years.

- Low: Trials covering less than 2 years, or slice-in-time studies of LVRRs of less than 2 years in age.

Relevance of the study focus

High: More than ten sections of at least $100 \mathrm{~m}$

- Medium: Between one and ten sections of at least $100 \mathrm{~m}$

- Low: One section of at least $100 \mathrm{~m}$

Table 1. Weight of evidence (Gough et al., 2013)

\subsection{Synthesis of evidence}

The data were synthesised, using narrative methods, to indicate the sustainability of the technology as a function of the parameters that affect road pavement performance, namely geometry, structural design, maintenance history, traffic composition and natural environment (i.e. climate, soil type and topography).

\section{Summary of main findings}

Fifteen high-quality studies were identified which provided quantitative data that could be synthesised to answer the primary review question. Fourteen of the studies were associated with the materials used for the construction of LVRRs (see Figure 2) and one was to do with the means of carrying out maintenance.

\subsection{Road pavement construction types}

\subsubsection{Block surfaces}

Two studies (Roughton, 2013; TRL, 2009) described the results of trials to assess the performance, over 2-5 years, of four types of block surfaces - fired clay bricks, concrete bricks, dressed stone and cobble stones (see Figure 3).

The extent to which block pavements may be considered a viable option for LVRR surfacing was found to be influenced by

the quality of construction

- compliance with brick crushing strength specifications $(20-25 \mathrm{MPa})$
- timely routine maintenance

- low tensile strength of joints.

The studies showed that all of the block surfaces considered are sustainable options and are particularly suited to highrainfall (>2000 mm/year) and weak-subgrade environments (i.e. California bearing ratio (CBR) less than 10\%). The most durable surfaces were found to be dressed stone and cobble, which could also be considered to be the most sustainable when the stones can be locally sourced and shaped. Fired clay and concrete bricks are less sustainable since energy is required for their production. However, dressed stone/cobble surfaces have a high roughness and therefore may not be suitable in cases where it is important to minimise road-user costs. The high roughness of these surfaces was also found to encourage motorcyclists and cyclists to use the road shoulder, causing edge wear that, over time, may cause water ingress into the pavement structure and thus accelerate deterioration.

\subsubsection{Concrete road surfaces}

Concrete road surfaces appear to provide an advantage over most other surfaces since they have low roughness when constructed properly and require little maintenance other than to the joints. However, they have high initial construction costs and are therefore mainly appropriate when all-season access with low road-user costs is required.

Two studies (Roughton, 2013; TRL, 2009) reported trials of concrete LVRRs in Vietnam, Cambodia and Lao PDR. Both 


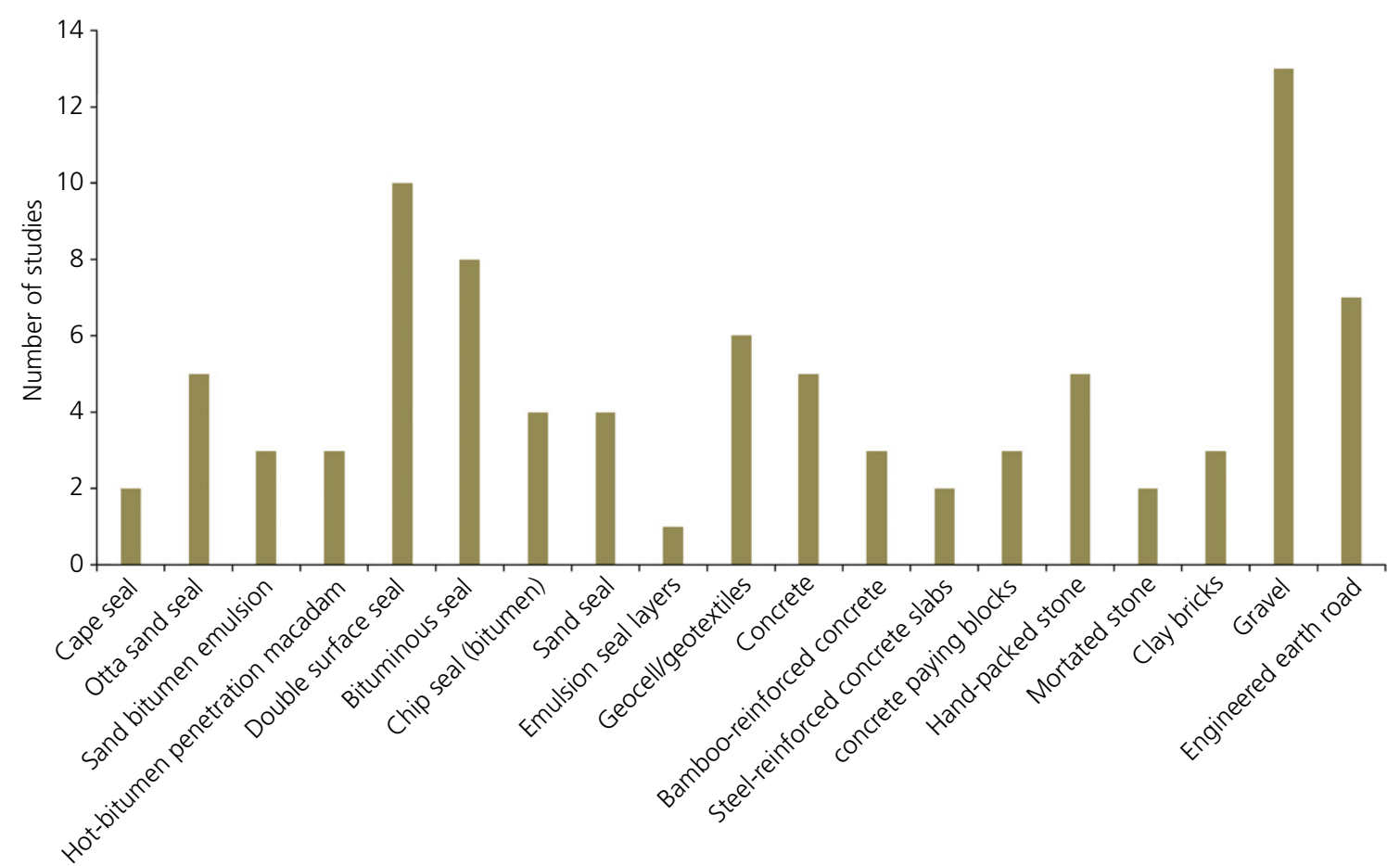

Figure 2. Rural road pavement construction technologies covered in the selected studies

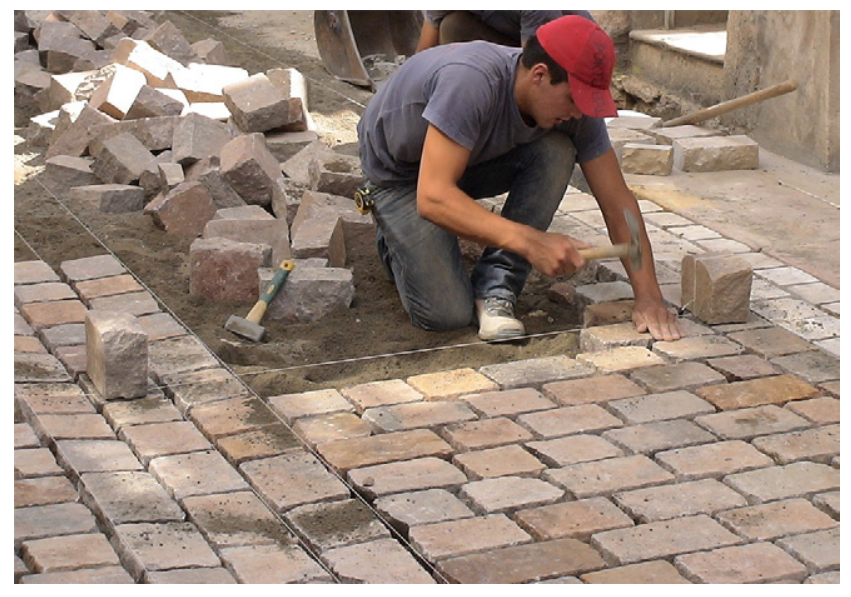

Figure 3. Construction of a dressed stone LVRR

studies described trials of bamboo-reinforced and non-reinforced concrete slabs, one described the use of a concrete geocell and the other assessed steel-reinforced concrete. The studies suggest that all four types of concrete surface performed satisfactorily in all environments considered. However, the performance of the surfaces in terms of roughness was shown to be directly related to the quality of construction. Inter-slab joints required maintenance after 2-3 years of operation. Steel-reinforced concrete pavements were found to perform only marginally better on weak subgrades compared with non-reinforced options and, as steel is a finite resource and relatively expensive, it may be surmised that steel is not a sustainable (or necessary) option.

Both studies showed that concrete sections reinforced with bamboo performed at least as well as those without reinforcement although bamboo-reinforced slabs were found to be more expensive to manufacture, in part due to the requirement to treat them chemically to prevent deterioration. However, a detailed supporting analysis carried out as part of one study (Roughton, 2013) found that the bamboo disintegrated over time and did not therefore provide reinforcement in the long term.

\subsubsection{Sealed surfaces}

Sealing roads helps to prevent moisture ingress and provides a satisfactory all-season running surface that can reduce roaduser costs through lower road roughness. As a consequence, seals can allow for the use of weaker (marginal) materials within the road pavement or a reduced thickness of more competent materials.

Ten studies assessed the performance of a variety of seals (see Table 2) and established that sealed LVRRs are sustainable from a durability point of view. Many of the roads examined were found to be performing adequately after the expected lifetime of the seal despite little or no maintenance, overloading in a number of cases and the use of materials below the 
Reference Technology $\quad$ T

Trial

Environment

Outcome: positive (+) or

negative (-) sustainability

Bhasin et al. (1987) Within sealed and unsealed roads 5-year monitoring of trial sections; India

Gourley and Greening Seals for quartzitic, lateritic, (1999) calcareous gravels and sand $\mathrm{road} / \mathrm{sub}$-bases

Lionjanga et al. (1987) Locally available calcrete bases and 7-year study of $9 \times 100 \mathrm{~m}$ sub-bases in sealed LVRRs sections; Botswana

Newill et al. (1987) Seals for volcanic cinder gravel bases and sub-bases

Pinard (2011)

Rolt et al. (2013)

Two-layered sealed, upgraded gravel LVRRs

Marginal materials

\section{Mozambique}

Double Otta, single Otta with sand 5-year trial of road sections; and sand seals

Sahoo et al. (2014)

Thin (20 mm) bituminous surfacing of LVRRs

Thin flexible seals: double stone chip/sand bitumen emulsions; triple bitumen surfacing: penetration macadam; Otta seal; dry/water bound macadam; single and double bitumen stone chip seal (DBST); armoured gravel

Wason and Oli (1982) Moorum road bases/sub-bases in sealed roads 5-year monitoring roads built Lao PDR

7.5-year trial road sections; Ethiopia

Back-analysis of two- and three-layer roads; Malawi Back-analysis of low-volume sealed road up to 10 years old

(1)
Traffic: 126000 ESAs

Gradients: flat (0-3\%) to steep (10\%-15\%)

Rainfall: 1435-2252 mm/year to Indian Road Congress specifications

24-37-month monitoring of roads built to dynamic cone penetrometer design method; Vietnam and Cambodia AADT: 68-281 commercial vehicles per day Subgrade: 41-119 MPa

Rainfall: 1400-3000 mm/year Traffic: 1000-330 000 ESAs

Gradients: flat to steep

20 sections monitored four times in 16 years; India

Rainfall: < $1000 \mathrm{~mm} / \mathrm{year}$
(+) Seals render Kankar sustainable as base/sub-base

(+) Seals enable natural gravel road base materials to be used successfully

(+) Calcretes as road bases and sub-bases

(-) Stabilised materials

(+) Surface dressed sections

(-) Unsealed gravel roads

(+) Two-layer pavement system for upgrading gravel roads

(+) Structural condition

(+-) Functional condition

(+) Otta seals with routine maintenance and periodic resealing (5 years for single seal, 10 years for double seal)

(+) Assuming maintenance after 5 years, $84 \%$ of sections performing satisfactorily

(+) Penetration macadam and bitumen DBST emulsion most durable options Traffic: $100-150$ carts and 10-15 heavy

(+) Sealed surfacing enables use vehicles per day 
recommended standards. One study (Pinard, 2011) suggested that this might indicate excessive over-design.

The review found that the extra thickness of surfacing material provided by double surface dressings and Cape seals makes them the most durable of the seals considered in a wide range of environments, particularly where gradients are steep, albeit at the expense of higher initial construction costs. In lowrainfall environments where low road roughness is a requirement (e.g. to transport agricultural goods to market undamaged), an emulsion sand seal may be an appropriate solution as it provides a satisfactory running surface and can be produced and maintained using locally available resources at low cost. Where annual rainfall is in excess of $2000 \mathrm{~mm} /$ year and low road roughness is required, bitumen, macadam-based seals or emulsion seals with stone chips may be a more appropriate choice. However, it should be noted that most seals require the use of scarce material resources and, with the exception of emulsion stone chip seals, necessitate the use of mechanical equipment for construction and maintenance.

\subsubsection{CONSTRUCTION AND MAINTENANCE REQUIREMENTS OF SEALED ROADS}

Poor construction quality was found to greatly affect the performance of both the seal and the road pavement. The studies reported that contractors who had developed prior experience of seals through the construction of trial sections performed better than contractors without such experience.

Seals deteriorate over time and it is therefore vital that timely routine maintenance is carried out to fix edge breaks, patch potholes and seal cracks. Routine maintenance prevents water ingress into the road structure and therefore prevents softening of the subgrade and possible premature failure. Routine maintenance notwithstanding, periodic re-sealing is required after approximately 5 years (for single seals) and 10 years (for double surface dressed seals) depending on the environmental conditions and, to a lesser extent, on the cumulative traffic loading.

\subsubsection{BASE AND SUB-BASE PERFORMANCE}

The performance of seals can be influenced by the base, subbase or subgrade performance. Lionjanga et al. (1987), for example, demonstrated a link between reflection cracking in seals and lime- or cement-stabilised bases.

\subsubsection{SHOULDER SEALING}

Four studies (Newill et al., 1987; Rolt et al., 2013; Roughton, 2013; TRL, 2009) demonstrated the benefit of sealing the shoulders of LVRRs, enabling a more stable moisture content regime to be maintained under the road pavement, particularly during periods of high rainfall. Sealed shoulders, in conjunction with an adequately designed road drainage system, facilitate the movement of moisture away from the wheel track, thereby preventing softening of load-bearing fine-grained subgrades and hence inhibiting accelerated road deterioration.

\subsubsection{Bases and sub-bases}

The ten studies listed in Table 2 also reported the performance of low-volume rural sealed roads constructed with a variety of bases and sub-bases. The studies found that, in general, LVRRs performed satisfactorily from a functional and structural point of view provided that the road was sealed, designed appropriately and well-constructed. Without periodic maintenance, roads with a single surface dressing started to show signs of significant deterioration after approximately 5 years (i.e. when resealing would be expected).

\subsubsection{UNCONVENTIONAL PAVEMENT DESIGNS}

Many road design procedures used in LICs suggest three-layer road pavement systems to adequately carry traffic loads experienced on high-volume roads. These designs have been adopted for LVRRs despite their low traffic volumes. However, two slice-in-time studies by Rolt et al. (2013) and Pinard (2011) investigated the performance of a number of two-layered sealed LVRRs founded on relatively strong subgrades (i.e. $\mathrm{CBR} \geq 30 \%$ ). The studies showed that, in many environments, two-layer designs perform satisfactorily (and beyond their design life in many cases), reducing construction costs by $166-233 \%$.

\subsubsection{STABILISATION}

In three of the studies (Lionjanga et al., 1987; Newill et al., 1987; Wason and Oli, 1982), the performance of marginal materials was found to be enhanced by chemical stabilisation (with lime and/or cement) provided that the stabilisation had been applied according to appropriate standards. Newill et al. (1987) also demonstrated that the behaviour of marginal materials with inappropriate grading characteristics could be enhanced by mechanical stabilisation with fines. Lionjanga et al. (1987) found that roads with bases made of stabilised calcretes did not perform satisfactorily. This was attributed to the lack of a stabilisation reaction in the calcrete and the consequent instability of the bases under traffic loads.

\subsubsection{Engineered earth roads (EERs)}

Although EERs provide the majority of access routes for most communities in LICs/LMICs, only one high-quality study was identified. This slice-in-time study by Rolt et al. (2008) assessed the performance of a large number of existing EERs in Cambodia. The different environments considered by the study were of limited variety in comparison with those that occur in all LICs/LMICs and therefore the study may be considered of limited applicability. Nevertheless, the study showed that a wide range of soils can be used to provide an adequate surface for motorised traffic of up to 50 vehicles per day (vpd) and higher (particularly if heavy trucks are absent) and in climates with rainfall of up to $2000 \mathrm{~mm} /$ year. 


\subsubsection{Construction and maintenance requirements of EERs}

Taking into account the findings from the study of Rolt $e t$ al. (2008), the generic prerequisites for the sustainable use of EERs include the following.

n In situ soil soaked strength of $\mathrm{CBR} \geq 15 \%$, although findings from research in non-LICs (Ahlvin and Hammitt, 1975) suggest that lower strengths (CBR $>8 \%$ ) may be sufficient albeit with higher maintenance requirements. Figure 4 shows the in situ assessment of the strength of an EER.

- Adequate design, with emphasis on drainage including sufficient camber, side, turnout and cross-drainage arrangements.

- Regular routine maintenance of camber and drainage.

- A longitudinal gradient, which progressively increases surface erosion and maintenance requirements, limited to below $6 \%$.

\subsubsection{Gravel roads}

For many years, natural gravel has been the commonly accepted solution for providing all-season rural access in developing regions. However, limited and depleted sources of gravel, life cycle costs and maintenance and environmental sustainability issues have prompted reconsideration of its use.

The included studies (Table 3) examined the performance of gravel roads in terms of road condition and the amount of gravel loss as a function of a number of factors, including gravel type and the environment. Although technically feasible for a wide range of situations, the sustainability of natural gravel surfacing was shown to be vitally dependent on a range of influential factors. The factors include

- achieving appropriate specifications relating to particle grading, plasticity and strength

- restricting application to roads carrying traffic of less than $200 \mathrm{vpd}$

- restricting application to environments with a rainfall of less than $2000 \mathrm{~mm} / \mathrm{year}$ and longitudinal gradients of less than $6 \%$

- ensuring the provision and maintenance of adequate camber and run-off arrangements through side drains, turnout (mitre) drains and cross-drainage

- timely provision of re-gravelling to replace material losses.

\subsection{Road maintenance approaches}

\subsubsection{The impact of road maintenance approaches on LVRR sustainability}

High-income countries aim to mechanise maintenance because labour is expensive and productivity can nearly always be increased using technology. However, in LICs and LMICs, heavy plant and its operation are significantly more expensive

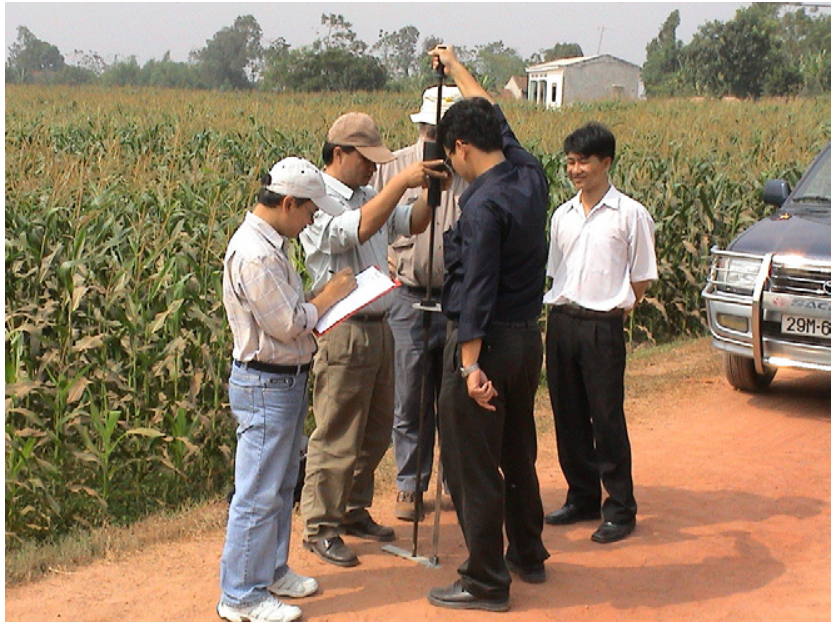

Figure 4. In situ dynamic cone penetrometer test of an engineered earth LVRR

than readily available labour. In addition, heavy plant (and replacement parts) are mainly imported and are therefore problematic to maintain. The maintenance of unpaved LVRRs thus offers scope for both intermediate equipment and labour.

The effectiveness of three different maintenance approaches (heavy equipment, intermediate equipment or labour-intensive methods) was reported by Jones (1984a). This study showed that intermediate technologies that were less expensive in terms of capital expenditure (e.g. tractor-towed graders (Figure 5)) and more labour-intensive methods could be considered at least as sustainable as heavy equipment (e.g. a mechanical grader). However, to achieve similar results it was found that labour-intensive technology requires adequate supervision and less expensive technologies require more frequent maintenance cycles.

\section{Discussion}

The review showed that the large majority of the technologies identified may be considered to be sustainable from an engineering point of view provided that their design, construction and maintenance are robust. However, the behaviour of roads over time is complex and can be affected by a number of factors, including the environment in which they operate, the design specification to which they are built, the way they are constructed, the quality of construction, the behaviour of their constituent materials and the frequency and effectiveness of their maintenance regimes. Furthermore, the behaviour of an individual component within a road is also influenced by the performance of other components. Therefore, since LVRRs deteriorate over time, monitoring programmes lasting at least until a component of the road has reached the limits of its physical life are required to properly assess durability. During this time, the performance of the road and the environment should also be periodically recorded. Since many sealed LVRRs are designed to last in the region of 20 years, with perhaps the application of two or three 


\begin{tabular}{|c|c|c|c|c|}
\hline Authors & Technology & Trial & Environment & $\begin{array}{l}\text { Outcome: positive }(+) \text { or negative }(-) \\
\text { sustainability }\end{array}$ \\
\hline Bhasin et al. (1987) & $\begin{array}{l}\text { Within sealed and unsealed } \\
\text { roads }\end{array}$ & $\begin{array}{l}\text { 5-year monitoring of trial } \\
\text { sections; India }\end{array}$ & $\begin{array}{l}\text { Average annual rainfall: }<1000 \mathrm{~mm} / \text { year } \\
\text { AADT: }<300\end{array}$ & $\begin{array}{l}(+-) \text { Sustainable within a sealed road } \\
\text { pavement only }\end{array}$ \\
\hline Cook and Petts (2005) & Gravel roads & $\begin{array}{l}\text { Back-analysis of roads; } \\
\text { Vietnam }\end{array}$ & $\begin{array}{l}\text { Rainfall: } 800-4000 \mathrm{~mm} / \text { year } \\
\text { AADT: }<200 \\
\text { Gradient: }>6 \%\end{array}$ & (-) Gravel roads unsustainable \\
\hline Jones (1984b) & $\begin{array}{l}\text { Lateritic, coral, volcanic, } \\
\text { quartzitic, gravel }\end{array}$ & $\begin{array}{l}\text { 2-4-year monitoring of } \\
\text { existing roads; Kenya }\end{array}$ & $\begin{array}{l}\text { Rainfall: 500-2000 mm/year } \\
\text { Annual traffic: } 1533-81760\end{array}$ & $\begin{array}{l}\text { (-) Sustainable for 50-200 vpd } \\
\text { depending on gravel }\end{array}$ \\
\hline Newill et al. (1987) & $\begin{array}{l}\text { Volcanic cinder gravel } \\
\text { surfaces }\end{array}$ & $\begin{array}{l}\text { 2-year monitoring of sections; } \\
\text { Ethiopia }\end{array}$ & $\begin{array}{l}\text { Rainfall: } \sim 750 \mathrm{~mm} / \text { year } \\
\text { AADT: } 150-200 \mathrm{vpd}\end{array}$ & (-) Gravel roads unsustainable \\
\hline Roughton (2013) & $\begin{array}{l}\text { Gravel control sections within } \\
\text { a wider study of alternative } \\
\text { surfacing }\end{array}$ & $\begin{array}{l}\text { 5-year monitoring of trial } \\
\text { sections; Lao PDR }\end{array}$ & $\begin{array}{l}\text { Rainfall: } \sim 1500 \mathrm{~mm} / \text { year } \\
\text { Traffic: } 126000 \mathrm{ESAs} \\
\text { Gradient: flat }(0-3 \%) \text { to steep } \\
\quad(10-15 \%)\end{array}$ & $\begin{array}{l}\text { (+-) Sustainable when sealed and } \\
\text { providing that resealing can take } \\
\text { place periodically }\end{array}$ \\
\hline TRL (2009) & $\begin{array}{l}\text { Gravel control sections within } \\
\text { a wider study of alternative } \\
\text { surfacing }\end{array}$ & $\begin{array}{l}\text { 24-37-month monitoring of } \\
\text { trial sections; Vietnam and } \\
\text { Cambodia }\end{array}$ & $\begin{array}{l}\text { Rainfall: } 1400-3000 \mathrm{~mm} / \mathrm{year} \\
\text { Traffic } 1000-330000 \mathrm{ESAs} \\
\text { Gradient: flat to steep }\end{array}$ & $\begin{array}{l}\text { (+-) Sustainable when sealed and } \\
\text { providing that resealing can take } \\
\text { place periodically }\end{array}$ \\
\hline
\end{tabular}




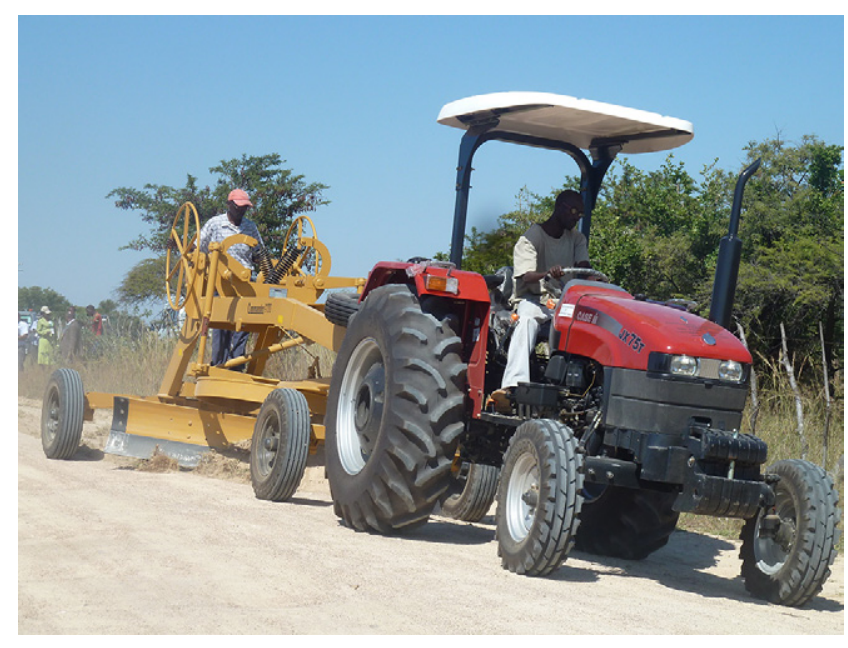

Figure 5. Tractor-towed grader in operation

planned periodic maintenance treatments in that time, it may be argued that such experiments should take place over at least two planned maintenance cycles so that the effect of maintenance may be established and life cycle costs determined. Clearly, these types of experiments are costly and problematic to undertake.

This review found only one study that was carried out over such a period (Wason and Oli, 1982), although road condition data were captured on only four occasions. Five other studies reporting experiments to determine the performance of LVRRs and their components were carried out over 5-7.5 years and one other study described an experiment lasting 2-3 years (see Tables 2 and 3). However, none of these studies captured the impacts of maintenance. Three other slicein-time studies (Gourley and Greening, 1999; Pinard, 2011; Rolt et al., 2013) captured the performance of roads at different stages of their life cycles and considered the impacts of maintenance. Five studies indicated the environmental conditions in which gravel and/or earth roads may perform satisfactorily; one of these took into account the effects of maintenance (Jones, 1984a).

Considering that the vast majority of road transport routes in developing regions are still EERs and many communities rely on these for access, there appears to be a lack of research into EERs.

To this end and to address the above issues in an integrated fashion, Table 4 provides a framework to assess the sustainability of the technologies against some key indicators. The average score provided was calculated assuming that each of the key indicators has the same weighting and should therefore only be considered a guide to the sustainability of any of the technologies in a given context or environment. To use the approach in practice, a weighting should be applied to each indicator to reflect the particular environment at hand. For example, in a region that has a relatively strong subgrade and where it is necessary to have roads of low roughness (e.g. to minimise the cost of transporting crops that are easily damaged by rough roads), a lower weighting could be given to the indicator 'Suitability for use on weak subgrades' and a relatively higher one to that associated with 'Achieved road serviceability'. A variety of approaches that can utilise expert opinion to determine weighting factors can be used (e.g. Saaty, 1980).

There were also other issues associated with assessing sustainability. For example, none of the studies considered in this review were able to address whether the trialled technologies were economically, socially and environmentally sustainable. Several studies, however, recognised the complexity of these issues (e.g. Roughton, 2013; TRL, 2009). Therefore, studies are required that will build on the concepts presented, such as environmentally optimised design (TRL, 2009). Other studies are required that consider, at the strategic level, the economic, environmental and social sustainability of a variety of rural road design, construction, maintenance and rehabilitation options. In the light of climate change, studies should also be carried out to examine how predicted changes in the climate and, in particular, the occurrence of extreme weather events may influence both strategy and design choices of LVRRs.

\section{Road institutions context}

It is important to note that the selection of a sustainable technology is related not just to the technology itself, but also to the institutional structure of the road administration in which the technology is implemented. For example, sustainability depends on the country context and on the parallel interventions that might be put in place, such as training of local engineers and contractors to make the chosen technology work as effectively as possible.

Selecting a sustainable technology needs to be viewed from the perspective of the decision maker who triggers the construction of a new road or agrees to provide funds for maintenance. This could be a donor agency, a road fund, the ministry of finance, local government, or another responsible ministry. Sustainability therefore needs to be considered in the context of the way road organisations are managed. Examples include the following.

(a) Roads managed and financed by a traditional district council. Typically, there is an acute shortage of qualified technical staff; work is often done by force account, but may also be carried out by local contractors. Design and supervision is problematic and therefore sustainable LVRR technology should be

(i) simple and easy to implement with little supervision 


\begin{tabular}{|c|c|c|c|c|c|c|c|c|c|c|c|c|c|c|}
\hline Technology & 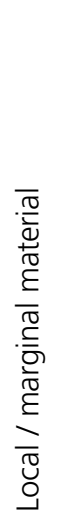 & 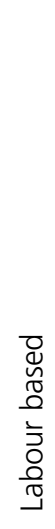 & 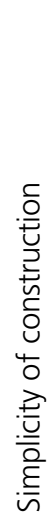 & 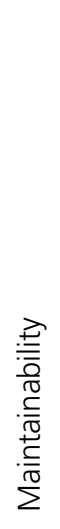 & 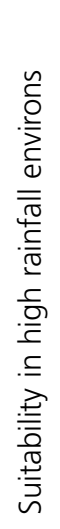 & 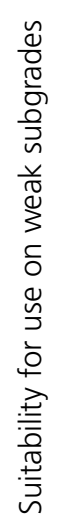 & 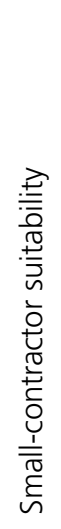 & 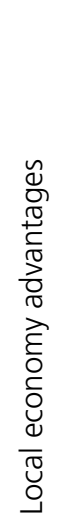 & 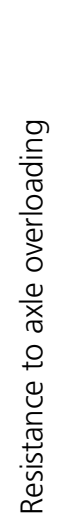 & 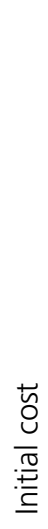 & 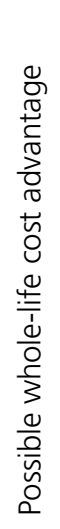 & 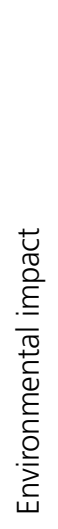 & 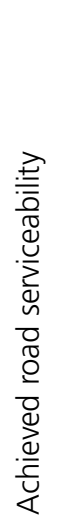 & 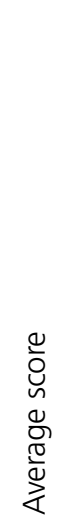 \\
\hline \multicolumn{15}{|l|}{ Sealed surfaces } \\
\hline Emulsion sand seals & 1 & 1 & 1 & 3 & 4 & 3 & 1 & 2 & 3 & 1 & 3 & 2 & 2 & $2 \cdot 1$ \\
\hline Emulsion stone chip seals & 3 & 1 & 2 & 2 & 2 & 3 & 1 & 2 & 3 & 2 & 2 & 2 & 2 & $2 \cdot 1$ \\
\hline Sealed dry-bound macadam & 3 & 3 & 2 & 1 & 2 & 2 & 2 & 3 & 2 & 2 & 2 & 3 & 2 & $2 \cdot 2$ \\
\hline Sealed water-bound macadam & 3 & 3 & 2 & 1 & 2 & 3 & 2 & 3 & 2 & 2 & 2 & 3 & 2 & $2 \cdot 3$ \\
\hline Hot-bitumen stone chip seals & 3 & 2 & 2 & 2 & 2 & 3 & 2 & 2 & 3 & 2 & 2 & 3 & 2 & $2 \cdot 3$ \\
\hline Penetration macadam & 3 & 3 & 2 & 2 & 2 & 3 & 2 & 2 & 3 & 2 & 2 & 4 & 2 & $2 \cdot 5$ \\
\hline Unsealed water-bound macadam & 2 & 2 & 2 & 4 & 4 & 3 & 2 & 3 & 3 & 1 & 4 & 3 & 4 & $2 \cdot 8$ \\
\hline Otta seals & 4 & 2 & 2 & 2 & 2 & 2 & 2 & 3 & 2 & 2 & 2 & 3 & 2 & $2 \cdot 3$ \\
\hline Sealed armoured gravel & 2 & 3 & 2 & 2 & 2 & 3 & 2 & 3 & 4 & 2 & 2 & 2 & 2 & $2 \cdot 4$ \\
\hline \multicolumn{15}{|l|}{ Block surfaces } \\
\hline Dressed stone/cobbles & 1 & 1 & 2 & 2 & 1 & 1 & 1 & 1 & 1 & 3 & 2 & 1 & 4 & $1 \cdot 6$ \\
\hline Fired clay bricks & 1 & 1 & 2 & 2 & 3 & 1 & 1 & 1 & 2 & 2 & 2 & 2 & 3 & $1 \cdot 8$ \\
\hline Concrete bricks & 2 & 1 & 2 & 2 & 3 & 1 & 1 & 2 & 1 & 3 & 2 & 1 & 2 & $1 \cdot 8$ \\
\hline \multicolumn{15}{|l|}{ Concrete surfaces } \\
\hline Steel-reinforced concrete & 2 & 2 & 3 & 1 & 1 & 1 & 2 & 3 & 1 & 4 & 2 & 3 & 1 & $2 \cdot 0$ \\
\hline Bamboo-reinforced concrete & 2 & 2 & 2 & 1 & 1 & 2 & 1 & 2 & 1 & 4 & 2 & 2 & 1 & $1 \cdot 8$ \\
\hline Non-reinforced concrete & 2 & 2 & 2 & 1 & 1 & 2 & 1 & 2 & 1 & 4 & 2 & 2 & 1 & $1 \cdot 8$ \\
\hline \multicolumn{15}{|l|}{ Bases } \\
\hline Lime-stabilised base/sub-base & 1 & 2 & 3 & 3 & 3 & 3 & 1 & 2 & 2 & 2 & 2 & 3 & 3 & $2 \cdot 3$ \\
\hline Cement-stabilised base/sub-base & 1 & 2 & 3 & 3 & 2 & 3 & 1 & 2 & 2 & 2 & 2 & 2 & 3 & $2 \cdot 2$ \\
\hline Emulsion-stabilised sub-base & 1 & 4 & 4 & 2 & 2 & 3 & 4 & 3 & 2 & 3 & 2 & 4 & 3 & $2 \cdot 8$ \\
\hline Two-layer pavement & 1 & 3 & 1 & 3 & 2 & 2 & 1 & 2 & 3 & 1 & 3 & 3 & 2 & $2 \cdot 1$ \\
\hline Unsealed natural gravel & 1 & 3 & 1 & 4 & 4 & 4 & 1 & 2 & 3 & 1 & 3 & 3 & 3 & $2 \cdot 5$ \\
\hline Engineered earth road & 1 & 2 & 1 & 3 & 4 & 3 & 1 & 2 & 3 & 1 & 3 & 1 & 3 & $2 \cdot 2$ \\
\hline
\end{tabular}

Table 4. Trial technologies against some key markers (after Roughton, 2013; TRL, 2009): 1 = advantage; 2 = possible advantage; 3 =neutral; 4 = disadvantage. An average value of less than 3 may suggest that the technology may be considered to be sustainable when used appropriately department exists to manage roads. Such organisations are usually given reasonable budgets for maintenance and employ technically qualified staff including private-sector contractors. Sustainable technology in this context

(i) could use advanced engineering technology

(ii) should not require close supervision for construction and maintenance (b) Roads managed and financed by a central government roads department. Typically, a special-purpose rural roads 
(iii) should be robust enough to perform adequately under irregular (and often underfunded) maintenance

(c) Contracted-out management and maintenance. In this situation, the roads are managed and maintained by consultants and contractors working as agents for local road agencies. Within a competitive enabling environment, all road works are audited. In such cases, sustainable technology can use cutting-edge engineering technology because the work is properly designed, the contractor is effectively supervised and all work is subject to a detailed financial audit.

\section{Other factors not present in the studies}

At the outset of the review it was hoped that studies would be found that could provide evidence of the use of nonengineering-driven technologies to facilitate, for example

\section{the development of policies and strategies}

- the appraisal of investment in rural road technologies economic tools such as HDM-4 have been used on behalf of road agencies and donor organisations to assess the economic benefits of high-volume roads; such tools perform life cycle analyses based on agency and road-user costs but, in the LVRR context, it would be necessary to utilise the findings from these tools within a multi-criteria approach that may capture the wider socio-economic benefits more satisfactorily (e.g. Ortiz-Garcia et al., 2005).

a the management of construction and maintenance of LVRRs.

\section{Conclusions}

There is a sufficient evidence base of technologies that can be used to improve upon the functional and structural performance of earth or gravel LVRRs in LICs/LMICs. These technologies may be considered to be sustainable in engineering terms in specific environments. However, strictly from the evidence of the review alone, it is not possible to suggest that these technologies are financially, economically, operationally, environmentally or socially sustainable in all environments. However, the evidence suggests that well-designed roads using available resources, under good construction supervision and subject to appropriate maintenance practice will yield a sustainable road from a wide variety of materials in a wide variety of environments. Furthermore, the selection of sustainable technologies to suit any particular environment may be inferred from the body of existing research based on sound criteria and subsequent analysis drawing on the wealth of existing experience.

It is important to stress that the findings of this review should be considered in a holistic manner by taking into account not only the explicit engineering-driven knowledge extracted but also the wider social, economic and institutional environment of the road sector. By so doing, the value of the review may be maximised and the findings can be transferred to other contexts. This can be achieved with the use of engineering judgement and expertise that will aim at identifying the commonalities of the prevailing conditions. In particular, the sustainability of the technology should be examined following a methodology such as that suggested in this paper based on appropriately defined measures and associated weighting factors that sufficiently reflect the conditions in the environments concerned.

\section{Recommendations for policy and practice}

(a) To consider revising LVRR design standards so that they are performance-based rather than specificationbased. This would encourage further innovation, including

(i) two-layered LVRR pavement designs

(ii) the use of marginal materials

(iii) the use of alternative surface materials

(iv) the development of environmentally optimised design

(v) feasible technology options

(vi) the development of more effective quality assurance regimes.

(b) To encourage whole-life cost approaches that adequately consider construction and maintenance costs, vehicle operating, accident and environmental costs, and whole-life socio-economic benefits.

(c) To provide a facilitating environment that ensures that LVRRs are constructed to the given design, materials and construction standards.

(d) To introduce effective asset management practices.

(e) To consider institutional and political parallel interventions that may be in existence or put in place (e.g. the training of local engineers, contracts) to make the chosen technology work as effectively as possible.

\section{Acknowledgements}

The team from the EPPI-Centre is acknowledged with gratitude for its assistance throughout the review process. In particular, the continual guidance and comments provided by Ms Kelly Dickson throughout the review stage were invaluable. The patient assistance of $\mathrm{Mr}$ Jeff Brunton in helping the review team make best use of the EPPI-Reviewer software is also gratefully acknowledged. The review team are also grateful for the guidance and advice provided by the project's advisory group. The systematic review was funded by the DFID and the valuable advice provided by DFID's Mrs Liz Jones and Mr Suman Baidya throughout the review process is also noted with gratitude.

\section{REFERENCES}

Ahlvin R and Hammitt I (1975) Load-supporting capability of low-volume roads. Transportation Research Record 160: 198-203. 
Akpan U (2014) Impact of regional road infrastructure improvement on intra-regional trade in Ecowas. African Development Review 26(S1): 64-76.

Bhasin NK, Narinder K, Panchanan O et al. (1987) Use of low grade materials for road construction in rural areas. Indian Highways 15(5): 35-48.

Cook J and Petts R (2005) Rural Road Gravel Assessment Programme, Module 4: Final Report. Department for International Development, London, UK. See http://r4d.dfid.gov.uk/PDF/Outputs/SEACAP4.pdf (accessed 30/07/2015).

Gough D, Oliver S and Thomas J (2013) An Introduction to Systematic Reviews. Sage, London, UK.

Gourley CS and Greening PAK (1999) Collaborative Research Programme on Highway Engineering Materials in the SADC Region, Volume 1: Performance of Low Volume Sealed Roads: Results and Recommendations from Studies in Southern Africa. Department for International Development, London, UK.

Hodges JW, Rolt J and Jones TE (1975) Kenya Road Transport Cost Study: Research on Road Deterioration. Transport and Road Research Laboratory, Crowthorne, UK.

Jones T (1984a) The Kenya Maintenance Study on Unpaved Roads: Optimum Maintenance Strategies. Transport and Road Research Laboratory, Crowthorne, UK.

Jones T (1984b) The Kenya Maintenance Study on Unpaved Roads: Research on Deterioration. Transport and Road Research Laboratory, Crowthorne, UK.

Knox J, Daccache A and Hess T (2013) What is the Impact of Infrastructural Investments in Roads, Electricity and Irrigation on Agricultural Productivity? Collaboration for Environmental Evidence, Bangor, UK, Review 11-007. See http://www.environmentalevidence.org/SR11007.html (accessed 13/06/2016).

Lebo J and Schelling D (2001) Design and Appraisal of Rural Transport Infrastructure Ensuring Basic Access for Rural Communities. World Bank, Washington, DC, USA. See http://www-wds.worldbank.org/external/default/ WDSContentServer/WDSP/IB/2001/05/24/000094946_ 0105050456528/Rendered/PDF/multi0page.pdf (accessed 30/07/2015).

Lionjanga A, Toole T and Newill D (1987) The development of specifications for the use of low-grade calcretes in lightly trafficked roads in Botswana. Transportation Research Record 1106: 281-304.

Newill D, Robinson R and Aklilu K (1987) Experimental use of cinder gravels on roads in Ethiopia, Proceedings of the 9th Regional Conference for Africa on Soil Mechanics and Foundation Engineering, Lagos, Nigeria.

Ortiz-Garcıa JJ, Snaith MS and Costello SB (2005) Setting road maintenance standards by multi-criteria analysis. Proceedings of the Institution of Civil Engineers - Transport 158(3): 157-166, http://dx.doi.org/10.1680/tran.2005.158.3.157.

Pinard MI (2011) Performance Review of Design Standards and Technical Specifications for Low Volume Sealed Roads in
Malawi: Final Report. AFCAP, Wantage, UK. See http://r4d.dfid.gov.uk/PDF/Outputs/AfCap/unpavedroadsstandards-Malawi.pdf (accessed 30/07/2015).

Rolt J, Cook JR and Kackada H (2008) Behaviour of Engineered Natural Surfaced Roads: Experimental Evidence in Cambodia. SEACAP 19: Technical Paper No. 2.2. Transport Research Laboratory, Crowthorne, UK. See http://r4d.dfid.gov.uk/PDF/Outputs/SeaCap/SEACAP19_ TP2.2.pdf (accessed 30/07/2015).

Rolt J, Mukura K, Dangare F and Otto A (2013) Back Analysis of Previous Constructed Low Volume Rural Roads in Mozambique. AFCAP, Wantage, UK.

Roughton (2013) Monitoring Programme in Lao PDR (SEACAP 17): Monitoring Report. Roughton International Ltd, London, UK. See http://r4d.dfid.gov. uk/pdf/outputs/AfCap/AFCAP-GEN-099-B-MonitoringReport.pdf (accessed 30/07/2015).

Saaty TL (1980) The Analytic Hierarchy Process. McGraw-Hill, London, UK.

Sahoo U, Ahmed S and Reddy K (2014) Long-term performance evaluation of rural road pavements in India. Proceedings of Geo-Hubei 2014: Design, Analysis, and Asphalt Material Characterization for Road and Airfield Pavements (Lee JL, Hossain Z and Hu X (eds)). ASCE, Reston, VA, USA, Geotechnical Special Publication no. 246, pp. 91-98.

Thomas J, Brunton J and Graziosi S (2010) EPPI-Reviewer 4.0: Software for Research Synthesis. EPPI-Centre, Social Science Research Unit, University of London, London, UK.

TRL (Transport Research Laboratory) (2009) Mid Term Pavement Condition Monitoring of the Rural Road Surfaces Research: Final report: SEACAP 27. Transport Research Laboratory, Crowthorne, UK. See http://r4d.dfid.gov.uk/PDF/Outputs/ SeaCap/SEACAP27-FinalReport.pdf (accessed 30/07/2015). Wason OP and Oli P (1982) Comparative evaluation of different low cost specifications for rural road sections in black cotton soil areas. Indian Highways 10(7): 39-53.

WB (World Bank) (2015) Country and Lending Groups. World Bank, Washington, DC, USA. See http://data.worldbank. org/about/country-and-lending-groups (accessed 13/06/2016).

\section{HOW CAN YOU CONTRIBUTE?}

To discuss this paper, please email up to 500 words to the editor at journals@ice.org.uk. Your contribution will be forwarded to the author(s) for a reply and, if considered appropriate by the editorial board, it will be published as discussion in a future issue of the journal.

Proceedings journals rely entirely on contributions from the civil engineering profession (and allied disciplines). Information about how to submit your paper online is available at www.icevirtuallibrary.com/page/authors, where you will also find detailed author guidelines. 